\title{
Effect of Superimposed Vibrations on Droplet Oscillation Modes in Prilling Process
}

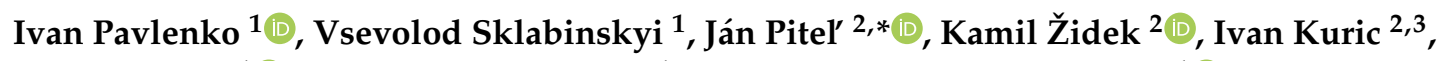 \\ Vitalii Ivanov ${ }^{1}$ (D), Maksym Skydanenko ${ }^{1}$ and Oleksandr Liaposhchenko ${ }^{1}$ (D) \\ 1 Faculty of Technical Systems and Energy Efficient Technologies, Sumy State University, \\ 2 Rymskogo-Korsakova St., 40007 Sumy, Ukraine; i.pavlenko@omdm.sumdu.edu.ua (I.P.); \\ v.sklabinskyi@pohnp.sumdu.edu.ua (V.S.); ivanov@tmvi.sumdu.edu.ua (V.I.); \\ m.skydanenko@pohnp.sumdu.edu.ua (M.S.); o.liaposhchenko@pohnp.sumdu.edu.ua (O.L.) \\ 2 Faculty of Manufacturing Technologies, Technical University of Košice, 1 Bayerova St., \\ 08001 Prešov, Slovakia; kamil.zidek@tuke.sk (K.Ž.); ivan.kuric@fstroj.uniza.sk (I.K.) \\ 3 Faculty of Mechanical Engineering, University of Žilina, 8215/1 Univerzitná St., 01026 Žilina, Slovakia \\ * Correspondence: jan.pitel@tuke.sk
}

Received: 24 April 2020; Accepted: 8 May 2020; Published: 11 May 2020

\begin{abstract}
This article was aimed to solve an urgent problem of ensuring quality for prilling processes in vibrational prilling equipment. During the research, the need for the application of vibrational prilling to create a controlled impact on the process of jet decay on droplets with the proper characteristics was substantiated. Based on the experimental and theoretical studies of the process of decay of a liquid jet into drops, axisymmetric droplet oscillation modes for the different frequencies were observed. Frequency ranges of transition between modes of decay of a jet into drops were obtained. As a result, the mathematical model of the droplet deformation was refined. The experimental research data substantiated this model, and its implementation allowed determining the analytical dependencies for the components of the droplet deformation velocity. The proposed model explains the existence of different droplet oscillation modes depending on the frequency characteristics of the superimposed vibrational impact. Based on an analytical study of the droplet deformation velocity components, the limit values of the characteristics defining the transition between the different droplet oscillation modes were discovered. Analytical dependencies were also obtained to determine the diameter of the satellites and their total number.
\end{abstract}

Keywords: prilling; droplet deformation; surface tension; superimposed vibrations

\section{Introduction}

During the dispersion of a liquid through a perforated shell in the vibrational priller, the geometric characteristics of holes for obtaining droplets are crucial for the creation of the energy-efficient prilling equipment [1] of nitrogen and complex mineral fertilizers [2]. At the same time, there is no single mechanism of liquid jet decay [3], and different mechanisms of liquid decay into droplets [4] are determined by both its physical properties [5] and the design parameters of the equipment.

Theoretical studies of the process of liquid jet decay into droplets under the action of its own oscillations [6] is the first, major step of theoretical and experimental studies to develop reliable mathematical models and to create calculation techniques for designing prillers. These models should spray the liquid into prills [7] with subsequent crystallization [8]. Moreover, the study of physical processes that affect the size of droplets allows designing new prillers to obtain monodisperse granules [8]. In this regard, the theoretical description of the liquid jet motion is based on jet theory $[9,10]$. 
From a different point of view, drop decay was extensively studied by Padday already in 1970s. Thereafter, in the 1990s, Kholin and Sklabinskyi developed fundamentals of the intensification of internal currents in drop moving in gas flow with a cross velocity gradient.

Investigations of the liquid phase dispersion process in perforated shells [11] to create equipment for producing of nitrogen fertilizers [12] from their melts are considered in work on dust emission [13]. The dispersion performance during the mass transfer processes in pulsed solvent columns was presented in an article on dispersion performance [14]. The use of the axial dispersion model for evaluation of the mass transfer coefficient in a perforated rotating disc contactor was presented in research on the dispersion model [15]. The computational approach for solving the coupled thermal and aerodynamic problems in technological equipment with perforated shells was proposed in a paper on air distribution in perforated shells [16]. The influence of temperature on granule formation for organic suspensions was studied in a paper on fluidized bed temperature [17].

Fluid jet behavior [18] out of holes depends on different conditions. However, the fluctuations show that the axisymmetric ellipsoidal shape of the formed droplet is permanently changing. Thus, the axes of the elliptical meridional cross-section of the jet are changed alternately under the action of capillary forces $[19,20]$. The amplitude of these oscillations gradually decreases, and the jet surface loses stability due to the unstable waves [21], surface tension-induced global instability [22], occurance of the Rayleigh-Plateau unstable modes [23], free-surface shear layer instabilities [24], and gas velocity oscillations [25], which ultimately leads to the decay of the liquid jet into droplets.

Herewith, Sklabinskyi and Skydanenko found an approximate solution of Navier-Stokes equations in cylindrical coordinates to describe fluid flow considering the hypothesis that the maximum axial velocity component is located at the jet axis. As a result, it is theoretically and experimentally confirmed that there are inherent transverse oscillations in the jet by changing the radial velocity component. Similar studies on the effect of oscillation frequency on the stability of the droplet shape [26] and its monodispersity [27] are additionally presented in the works [28,29].

Issues of increasing efficiency of prilling and heat and mass transfer equipment, as well as of technological features of their design and manufacturing are considered in the works [30-32].

According to the analysis mentioned above, the aim of this research was to create a refined mathematical model that describes the effect of superimposed vibrations on droplet deformations, which is based on an experimental study of droplet oscillation modes. The following objectives have been reached to achieve this goal:

- Substantiation of the need for the application of vibrational prilling to create a controlled impact on the process of jet decay on droplets with a given size, shape, and the degree of monodispersity;

- Experimental research of the droplet oscillation modes for the different frequencies;

- Creation of a refined mathematical model of droplet deformation;

- Determination of analytical dependencies to determine velocity components under experimentally obtained peculiarities of droplet deformation;

- Obtaining a condition for the droplet shape stability and evaluating the characteristics of their secondary decay.

\section{Materials and Methods}

In the process of fluid leakage from the holes of the prilling equipment, the critical velocity of the jet decay into droplets can be determined from the equilibrium state condition as the equality of the forces of surface tension [33] and environmental resistance [34]:

$$
\sigma \pi d=3 \mu v_{c r} \pi d,
$$

where $d$-diameter of a droplet; $\sigma, \mu$-surface tension coefficient and dynamic viscosity, respectively; $v_{c r}$-critical velocity value. 
As a result, the following dependence should be obtained:

$$
\sigma v_{c r}=\frac{\sigma}{3 \mu} .
$$

For the laminar jet, formula (2) indicates that the critical velocity does not depend on the size of the formed droplets. Thus, it it valuable to create scientific and theoretical fundamentals of the process of the controlled formation of a drop using the below-presented effect of superimposed vibrations on droplet oscillation modes.

It should be noted that the dependence mentioned above corresponds to the following critical value of the dimensionless criterion:

$$
C a_{c r}=\left(\frac{W e}{R e}\right)_{c r}=0.33,
$$

where $\mathrm{Ca}$-capillary number as a similarity criterion in hydrodynamics as a ratio of forces of viscous friction and surface tension [35]; Re-Reynolds number as a ratio of inertial forces to viscous friction forces [36]; We-similarity criterion that determines the ratio of inertia forces to surface tension forces [37].

$$
C a=\frac{\mu v}{\sigma} ; R e=\frac{\rho v d}{\mu} ; W e=\frac{\rho d v^{2}}{\sigma},
$$

where $\rho$-density; $v$ —velocity as a liquid efflux rate.

According to Formula (2), to create a controlled impact on the process of jet decay into droplets of a given size and degree of monodispersity, a vibration effect is implemented and realized in the vibration prilling equipment. The experimental setup and the corresponding design scheme are presented in Figure 1. The stand is also equipped with a pneumatic system for measuring the liquid level and a control panel.

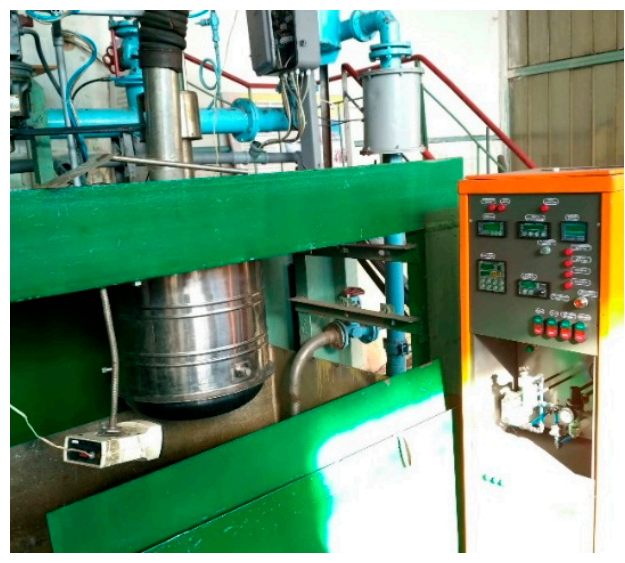

(a)

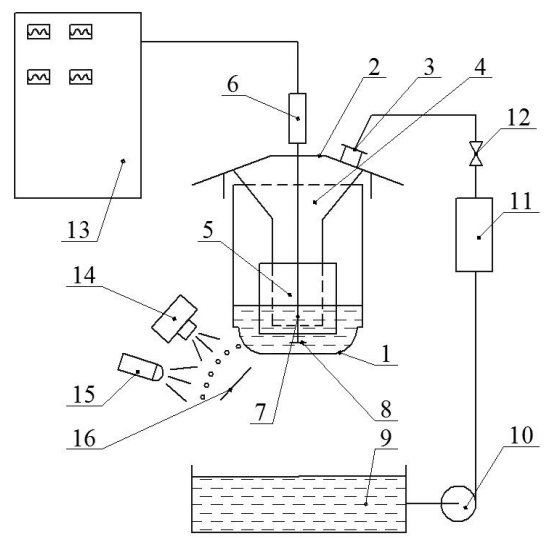

(b)

Figure 1. The experimental setup (a) and the corresponding design scheme (b): 1-basket; 2-housing; 3-pipe; 4-collector; 5-filter element; 6-vibrational actuator; 7-stock; 8-resonator; 9-buffer tank; 10—pump; 11—flow meter "Metran 370"; 12—valve; 13—control panel; 14-high-speed camera; 15-stroboscope; 16-screen.

The system consists of a transducer for the proportional conversion of the pressure drop and liquid level to a unified signal. The liquid level is regulated by the "Metran 100" level meter. Control of the vibrational signal from the perforated basket is carried out using the GDS-820S oscilloscope. The change of technological characteristics during the dispersion process is realized by measuring the flow rate and frequency with the consequent processing by means of the Matlab software $[38,39]$. 
The computer program generates a signal with the consequent its amplification and transfers to a magnetostrictive actuator (electromagnetic vibrator), which causes vibrations of the resonator. The last one is located above the central part of the perforated basket. The gap between the disc and the bottom provides a hydrodynamic interaction between the elements of the hydromechanical system. Due to this connection, the waves were propagated in the melt and reached the perforated basket. The oscillation frequency of the bottom was fixed by the vibrational sensor "DN-3M1" with the converter "PKV-02." A stroboscope was used to observe the decay of a liquid jet on droplets visually. The frequency signal was synchronized with the wave generator.

Due to that the melt of ammonium nitrate and water shows a similar behavior during dispersion, water under environmental conditions was used for experimental studies. The oscillation frequency was varied in the range of $200-800 \mathrm{~Hz}$ with an amplitude of $50 \mu \mathrm{m}$ to study an effect of superimposed vibrations on droplet oscillation modes. The obtained images were analyzed using the Object Detection Method using Matlab software [40].

Experimental research shows that jet decay occurs at the frequency of $240 \mathrm{~Hz}$ (Figure 2). In this case, the main droplet forms with a satellite. The average diameter of the satellite $d_{s 0}=0.92 \mathrm{~mm}$ is not significantly different from the average diameter of the droplet $d_{0}=1.04 \mathrm{~mm}$. At the beginning of this movement, the distance between the groups of droplets $L_{0}=3.8 \mathrm{~mm}$.

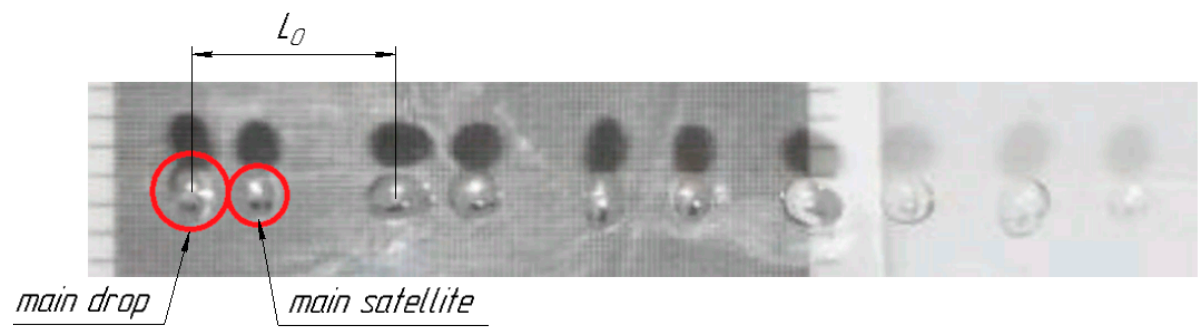

Figure 2. The decay of the jet into drops at the frequency of $240 \mathrm{~Hz}$.

After breaking the surface connection between the droplet and the satellite, secondary satellites formed with an average diameter $\Delta d=0.19 \mathrm{~mm}$. Diameters of the main droplet and the main satellite reduced to $d=0.94 \mathrm{~mm}$ and $d_{s}=0.84 \mathrm{~mm}$, respectively, and the distance between them decreased to $L_{0}=2.1 \mathrm{~mm}$.

At a frequency of $510 \mathrm{~Hz}$, the monodisperse jet decay mode was set (Figure 3).

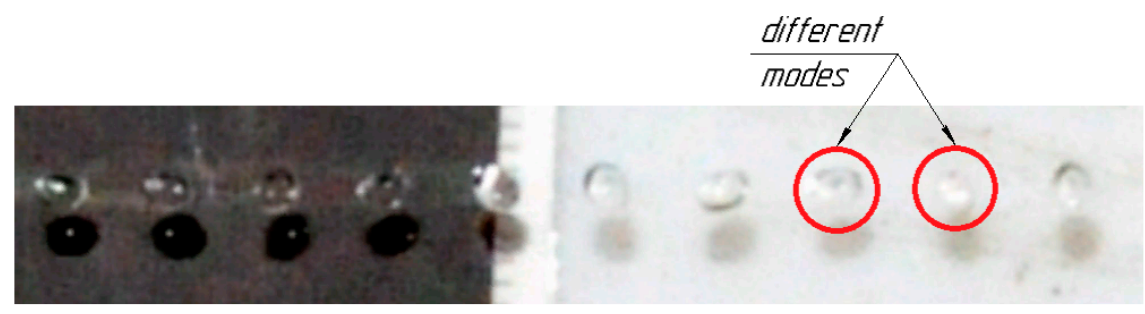

Figure 3. Droplet oscillation modes for the frequency of $510 \mathrm{~Hz}$.

As can be observed, the droplets have an ellipsoidal shape with alternating changes of the minor and major axes.

With a further increase in frequency, a polydisperse decay of the jet occurred. An increase in the frequency of up to $800 \mathrm{~Hz}$ led to jet spraying with the formation of a large number of relatively small secondary satellites (Figure 4). 


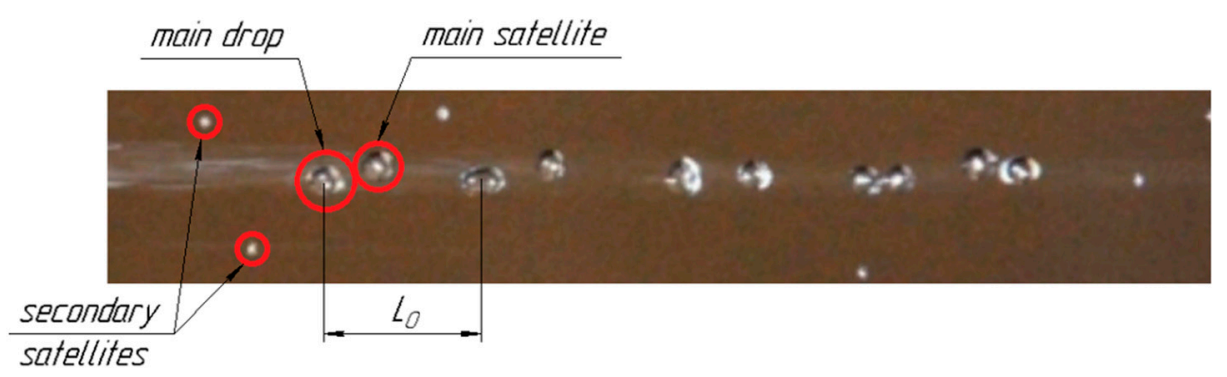

Figure 4. Secondary satellite formation at the frequency of $800 \mathrm{~Hz}$.

In this case, the average number of satellites can be approximately determined from the mass conservation law for the system "main drop—main satellite—secondary satellites":

$$
\frac{\pi}{6}\left(\Delta d^{3} n_{s}+d^{3}+d_{s}^{3}\right)=\rho \frac{\pi}{6}\left(d_{0}^{3}+d_{s 0}^{3}\right)
$$

by the following formula:

$$
n_{s}=\frac{\left(d_{0}^{3}-d^{3}\right)+\left(d_{s 0}^{3}-d_{s}^{3}\right)}{\Delta d^{3}} .
$$

To identify kinematic characteristics of droplet oscillations as the periodic change of its shape from spherical to ellipsoidal with an alternate change of its axes in radial cross-section, as has been experimentally studied (Figure 3), the condition of droplet mass conservation can be applied for deformations according to the design scheme presented in Figure 5:

$$
\rho \frac{4}{3} \pi(R+\Delta r)^{2}(R+\Delta z)=\rho \frac{4}{3} \pi R^{3},
$$

where $\rho$-density of a liquid; $R$-radius of a droplet in the quasi-equilibrium state; $\Delta r, \Delta z$-deviations of the radial and axial axes of the axisymmetric ellipsoid, respectively.

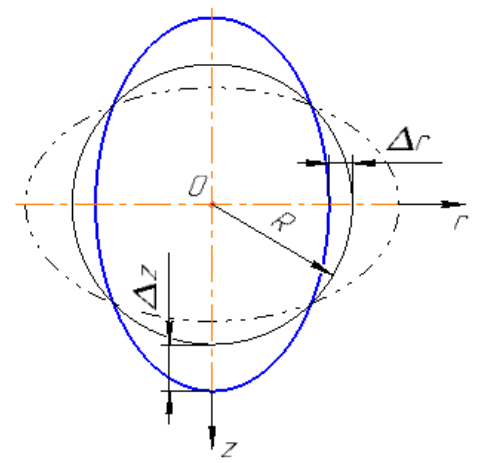

Figure 5. The design scheme of droplet deformations.

The statement mentioned above about the alternately changing axes is confirmed by the following dependence between the parameters $\Delta r$ and $\Delta z$, which are determined from Equation (7):

$$
\Delta z=-\frac{R \Delta r(2 R+\Delta r)}{(R+\Delta r)^{2}}
$$

where the sign "-" indicates that an increase in the radial size of the droplet leads to a decrease in its axial size. 
As a result of experimental studies, it was discovered that transverse oscillations in the fluid flow occur. According to this phenomenon, the radial velocity of the drop can be expressed in the following way:

$$
z v_{r}(r, z)=v_{r 0}(r) \sin \lambda z,
$$

where $v_{r 0}(\mathrm{r})$ - unknown radial velocity change function; $\lambda=2 \pi / L$-frequency parameter, inversely proportional to the wavelength $L$.

Next, the sign " $\Delta$ " will be skipped to make it easier to write analytical dependencies. The continuity equation is used to obtain the analytical dependencies for the velocity components, which in the cylindrical coordinate system is:

$$
\frac{\partial v_{z}(r, z)}{\partial z}+\frac{v_{r}(r, z)}{R+r}+\frac{\partial v_{r}(r, z)}{\partial r}=0
$$

where $v_{z}(r, z)$-axial velocity component that can be associated with the radial one using the following identical transformations:

$$
v_{z}(r, z)=\frac{\mathrm{d} z}{\mathrm{~d} t}=\frac{\mathrm{d} z}{\mathrm{~d} r} \frac{\mathrm{d} r}{\mathrm{~d} t}=\frac{\mathrm{d} z}{\mathrm{~d} r} v_{r}(r, z) .
$$

Differentiation of Equation (8) with respect to $r$ allows obtaining the following differential expression:

$$
\frac{\mathrm{d} z}{\mathrm{~d} r}=-\frac{2 R^{3}}{(R+r)^{3}}
$$

according to which Equation (11) takes the form:

$$
v_{z}(r, z)=-\frac{2 R^{3}}{(R+r)^{3}} v_{r}(r, z)
$$

Substituting Formula (13) with the continuity Equation (10), considering the proposed dependence (9) after identical transformations, allows obtaining a homogeneous differential equation with respect to an unknown function $v_{r 0}(r)$. After averaging along the wavelength:

$$
\int_{0}^{\pi \lambda / 2}\left\{\sin \lambda z \frac{\mathrm{d} v_{r 0}(r)}{\mathrm{d} r}+\left[\frac{\sin \lambda z}{R+r}-\frac{2 R^{3}}{(R+r)^{3}} \lambda \cos \lambda z\right] v_{r 0}(r)\right\} \mathrm{d} z=0
$$

this equation takes the following form:

$$
\frac{\mathrm{d} v_{r 0}(r)}{\mathrm{d} r}+\left[\frac{1}{R+r}-\frac{2 R^{3}}{(R+r)^{3}} \lambda\right] v_{r 0}(r)=0 .
$$

After integration and entering dimensionless parameters (coordinate $\bar{r}$, the amplitude of the radial velocity $\bar{v}_{r 0}$, and velocity components $\bar{v}_{r}, \bar{v}_{z}$ ):

$$
\bar{r}=\frac{r}{R}=[-1 ; 0] ; \bar{v}_{r 0}=\frac{v_{r 0}}{v_{r 0}(0)} ; \bar{v}_{r}=\frac{v_{r}}{v_{r 0}(0)} ; \bar{v}_{z}=\frac{v_{z}}{v_{r 0}(0)}
$$

the dimensionless velocity components take the following form:

$$
\bar{v}_{r}(\bar{r})=\frac{1}{1+\bar{r}} e^{\frac{\bar{r}(2+\bar{r})}{(1+\bar{r})^{2}} \lambda R} \sin \lambda z ; \bar{v}_{z}(\bar{r})=-\frac{2}{(1+\bar{r})^{4}} e^{\frac{\bar{r}(2+\bar{r})}{(1+\bar{r})^{2}} \lambda R} \sin \lambda z
$$




\section{Results}

The expressions obtained for the velocity components are confirmed by studies previously carried out by Sklabinskyi and Skydanenko. They found that the radial velocity in the critical section increases from the jet axis to the surface. It destroys the jet and subsequent formation of droplets. However, the approach presented above allows one to evaluate the criterion, which preserves the monodispersity of the obtained prills. For this purpose, the dimensionless radial velocity amplitude was investigated separately:

$$
\bar{v}_{r 0}(\bar{r})=\frac{1}{1+\bar{r}} e^{\frac{\bar{r}(2+\bar{r})}{(1+\bar{r})^{2}} \lambda R} .
$$

Decomposition of this dependence into a Maclaurin's series with respect to the parameter $\bar{r}$ considering the first-order terms allows linearizing the expression for the radial velocity amplitude and, accordingly, obtaining a tangent to the curve " $v_{r 0}-\bar{r}$." In this case, near the surface of the droplet, it can be written the following approximation:

$$
\bar{v}_{r 0}(\bar{r}) \approx 1+(2 \lambda R-1) \bar{r} .
$$

The resulting expression indicates that in the case of the limit value $\lambda_{c r}=1 /(2 R)$ of the parameter $\lambda$, the radial velocity has zero radial gradient on the droplet surface. Moreover, in the case of $\lambda<\lambda_{c r}$, which corresponds to the wavelengths $L>4 \pi R$, the radial velocity changes its sign inside the droplet. The relevant limit value $\bar{r}_{*}$ is determined from the condition of the amplitude extremum (18) and is equal to:

$$
\bar{h}_{*}=-\bar{r}_{*}=1-\frac{1}{\sqrt{n}},
$$

where the ratio of the wavelength to its limiting value is introduced as:

$$
n=\frac{L}{L_{c r}}=\frac{2 \pi / \lambda}{4 \pi R}=\frac{1}{2 \lambda R}
$$

Thus, it can be shown that the exceeding of the dimensionless radial velocity of value $\bar{v}_{r 0}=1$ occurs inside the droplet at the following general formulation of distance from its surface:

$$
\bar{h}_{* *}=-\bar{r}_{* *}=1-\frac{1}{n^{\alpha}}
$$

where $\alpha$-a parameter thatcan be identified by minimizing the total square error:

$$
R(\alpha)=\sum_{i=1}^{N}\left[\alpha \ln n_{i}+\ln \left(1-\bar{r}_{* *}^{(i\rangle}\right)\right]^{2} \rightarrow \min ; \frac{\mathrm{d} R(\alpha)}{\mathrm{d} \alpha}=0,
$$

where $n_{i}, \bar{r}_{* *}^{\langle i\rangle}$-experimentally obtained points (Figure 6).

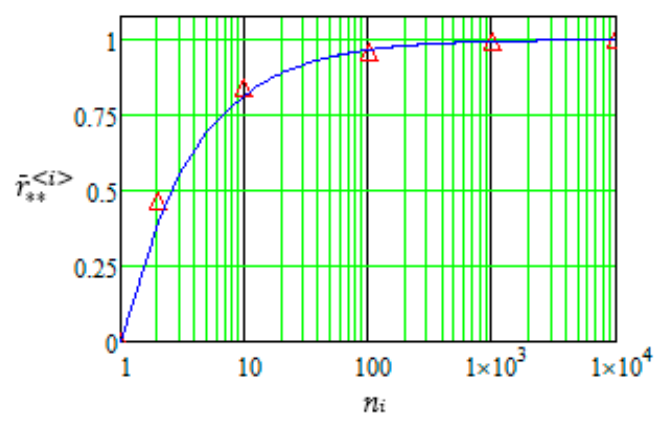

Figure 6. The dependence between the dimensionless radius $\bar{r}_{* *}$ and the ratio $n$. 
The use of the regression formula:

$$
\alpha=-\frac{\sum \ln n_{i} \ln \left(1-\bar{r}_{* *}^{(i)}\right)}{\sum \ln ^{2} n_{i}}
$$

allows obtaining the value $\alpha=2 / 3$. Consequently, Formula (22) takes the following form:

$$
\bar{h}_{* *}=-\bar{r}_{* *}=1-\frac{1}{n^{2 / 3}} .
$$

As a result of numerical calculations, the amplitude of dimensional radial velocity for different wavelengths is presented in Figure 7.

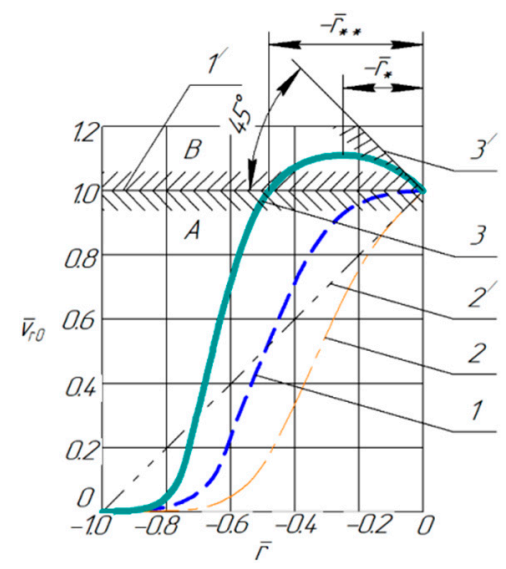

Figure 7. Changing the radial velocity amplitude over the radius of the droplet: A, B-zone of the constant and variable sign of the radial velocity gradient; 1-3-curves of the radial velocity amplitude; $1 /-3 /$ - tangential lines to the radial velocity at the droplet surface.

Additionally, the range of change in the diameter of the main satellite can be determined from the equation of mass conservation:

$$
d_{s}=\sqrt[3]{1-\left(2-\frac{1}{n^{\alpha}}\right)^{3}} d
$$

where $\alpha$-parameter that varies in the range of $1 / 2-2 / 3$ according to expressions (20) and (25).

The reliability of the analytically developed dependencies is confirmed by their comparison with the obtained experimental data. Particularly, it has been experimentally found that for the frequency of $f=240 \mathrm{~Hz}$, the jet decay is accompanied by the formation of the main droplet with an average diameter $d=1.04 \mathrm{~mm}$. The distance between the main droplets is $L_{0}=3.8 \mathrm{~mm}$ (Figure 2). In this case, the wave parameter $\lambda=2 \pi / L_{0}=1653 \mathrm{~m}^{-1}$. Its critical value $\lambda_{c r}=1 / d=962 \mathrm{~m}^{-1}$ corresponds to the wavelength $L_{c r}=6.5 \mathrm{~mm}$. The value of $n=\lambda_{c r} / \lambda=0.582$ allows evaluating the diameter of the satellite in the range of $0.91-0.97 \mathrm{~mm}$. Its average value $d_{s}=0.94 \mathrm{~mm}$ is consistent with the above-mentioned experimental value $0.92 \mathrm{~mm}$.

Similarly, for the vibration frequency of $f=510 \mathrm{~Hz}$ (Figure 3), diameters of the main droplet and the satellite are equal $d=0.94 \mathrm{~mm}$ and $d_{s}=0.84 \mathrm{~mm}$, respectively. In this case, the range $0.78-0.84 \mathrm{~mm}$ of the satellite diameter allows evaluating the average value of $0.81 \mathrm{~mm}$. Finally, it should be noted that the relative error is less than $4 \%$.

\section{Discussion and Conclusions}

In this article, the need for application vibrational prilling to create a controlled impact on the process of jet decay on droplets with a given size, shape, and degree of monodispersity was substantiated in terms of the dependence between the critical velocity and diameter. 
Theoretical and experimental research of the process of the liquid jet decay on droplets have been carried out, which is one of the main processes during vibrational prilling. As a result, the droplet oscillation modes for the different frequencies have been discovered. Notably, at relatively low frequencies, the jet decay occurs with the formation of the main droplet together with approximately the same satellite.

It has been found that as the frequency of vibration is increased, the connection between the droplet and the satellite breaks down. This leads to the formation of a row of relatively small secondary satellites. In this case, the diameters of droplets and the distance between the main droplets also decrease.

Based on experimentally set modes, a refined mathematical model of droplet deformations has been developed. This model is based on both the law of mass conservation and the continuity equation. As a result, the analytical dependencies for the velocity components have been obtained. The model allows theoretically justifying the change in the sign of the radial velocity gradient as a cause of the jet decay into droplets under the vibrational impact, as well as obtaining analytical dependencies to determine the diameter and the total number of satellites.

Additionally, the stability condition and decay characteristics of the axisymmetric droplet shape were determined. As a result, it was found that there are several modes, which depend on the frequency characteristics of the vibrational impact. Particularly, in the first mode, the radial velocity amplitude increases from zero in the droplet center to the maximum value on the surface. This mode corresponds to relatively low vibrational frequencies. This is realized to the limit when the wavelength is equal to the analytically obtained critical value. In the second mode, the radial velocity amplitude inside the droplet exceeds the critical value and reaches the maximum value at a certain distance from the surface, at which the radial velocity gradient changes its sign. This mode occurs at relatively high vibrational frequencies. It is accompanied by jet spraying with the formation of a large number of relatively small secondary satellites.

The reliability of the obtained results is confirmed by the discrepancy between the analytically obtained average diameter of satellites and the corresponding experimental value for the different frequencies of vibrational impact. Notably, the relative error does not exceed $4 \%$.

Finally, the obtained results can be helpful in the implementation of energy-efficient vibrational prilling equipment for producing high-quality prills with controlled characteristics and a high degree of monodispersity, as well as to improve the methodology of the design of the corresponding technological equipment. The practical results were already applied for the development of amplifiers for vibration actuators that provide a predetermined composition of the resulting prills. The corresponding vibrational prillers with an automatic control system were developed at Sumy State University and implemented at the fertilizer manufacturing enterprises JSC "Azot" (Cherkasy, Ukraine) and "Indian Farmers Fertilizer Cooperative Limited (IFFCO)" (Aonla, India).

Author Contributions: Conceptualization, V.S., I.P., and M.S.; methodology, I.P. and M.S.; software, I.K.; validation, O.L., V.I., and I.K.; formal analysis, J.P. and K.Ž.; investigation, M.S. and I.P.; resources, V.I. and I.K.; data curation, O.L.; writing—original draft preparation, K.Ž.; writing—review and editing, J.P.; visualization, M.S. and V.I.; supervision, V.S.; project administration, V.S. and J.P.; funding acquisition, J.P. All authors have read and agreed to the published version of the manuscript.

Funding: The research was supported by the Ministry of Education and Science of Ukraine within the project of Sumy State University "Creation of New Granular Materials for Nuclear Fuel and Catalysts in the Active Hydrodynamic Environment" (State reg. no. 0120U102036) and by the Project of the Structural Funds of the EU, ITMS code: 26220220103.

Conflicts of Interest: The authors declare no conflict of interest. 


\section{References}

1. Wu, Y.; Bao, C.; Zhou, Y. An innovated tower-fluidized bed prilling process. Chin. J. Chem. Eng. 2007, 15, 424-428. [CrossRef]

2. Wang, Y.; Jiang, X.W.; Yuan, H. Process calculation of mechanical ventilation prilling tower for ammonium nitrate. Huaxue Gongcheng Chem. Eng. 2013, 41, 69-74. [CrossRef] [PubMed]

3. Saito, S.; Abe, Y.; Kaneko, A.; Kanagawa, T.; Iwasawa, Y.; Matsuo, E.; Ebihara, K.I.; Sakaba, H.; Koyama, K.; Nariai, H. Experimental study on jet instability and breakup behavior in liquid-liquid system. In Proceedings of the International Conference on Nuclear Engineering, ICONE, Chiba, Japan, 21 May 2015; American Society of Mechanical Engineers (ASME): New York, NY, USA, 2015; Volume 2015, p. 118695.

4. Cheong, B.S.; Howes, T. Capillary jet instability under the influence of gravity. Chem. Eng. Sci. 2004, 59, 2145-2157. [CrossRef]

5. Yang, M.; Yan, L.; Wang, Y.; Gong, C.; Lu, J. Instability and interfacial coherent structure of free round turbulent jet. Nongye Jixie Xuebao Trans. Chin. Soc. Agric. Mach. 2016, 47, 35-44.

6. Sanyal, A.; Basu, S. Evaporation excites temporal sequence of resonant modes in a sessile droplet perturbed at constant frequency - Insights into the universal dynamics of mode transitions. Chem. Eng. Sci. 2018, 176, 294-305. [CrossRef]

7. Hoffmann, T.; Rieck, C.; Bück, A.; Peglow, M.; Tsotsas, E. Influence of granule porosity during fluidized bed spray granulation. Procedia Eng. 2015, 102, 458-467. [CrossRef]

8. Chen, C.W.; Lee, T. Round Granules of Dimethyl Fumarate by Three-in-One Intensified Process of Reaction, Crystallization, and Spherical Agglomeration in a Common Stirred Tank. Org. Process Res. Dev. 2017, 21, 1326-1339. [CrossRef]

9. Zhang, L.; Liu, W.; Zhang, Y. Calculation of teeter bed height of teetered bed separator based on jet theory. Powder Technol. 2016, 295, 225-233. [CrossRef]

10. Zhang, X.; Cao, S.; Li, D. Study of integrated dust control and dust removal technology based on wall-attached jet theory. Zhongguo Kuangye Daxue Xuebao J. China Univ. Min. Technol. 2019, 48, 495-502.

11. Skydanenko, M.; Sklabinskyi, V.; Saleh, S. CFD simulation of ammonium nitrate melt in a perforated rotating bucket. In Advances in Design, Simulation and Manufacturing (DSMIE 2018). Lecture Notes in Mechanical Engineering; Ivanov, V., Rong, Y., Trojanowska, J., Venus, J., Liaposhchenko, O., Zajac, J., Pavlenko, I., Edl, M., Peraković, D., Eds.; Springer: Cham, Switzerland, 2019; pp. 498-506.

12. Vakal, V.; Pavlenko, I.; Vakal, S.; Hurets, L.; Ochowiak, M. Mathematical Modeling of Nutrient Release from Capsulated Fertilizers. Period. Polytech. Chem. Eng. 2019. [CrossRef]

13. Skydanenko, M.; Sklabinskyi, V.; Saleh, S.; Barghi, S. Reduction of dust emission by monodisperse system technology for ammonium nitrate manufacturing. Processes 2017, 5, 37. [CrossRef]

14. Li, W.; Wang, Y.; Mumford, K.A.; Smith, K.H.; Stevens, G.W. Comparison of the axial dispersion performance of pulsed solvent extraction columns with Tenova pulsed column-kinetics internals and standard disc and doughnut internals. Solvent Extr. Ion Exch. 2018, 36, 387-400. [CrossRef]

15. Asadollahzadeh, M.; Hemmati, A.; Torab-Mostaedi, M.; Shirvani, M.; Ghaemi, A.; Mohsenzadeh, Z.S. Use of axial dispersion model for determination of Sherwood number and mass transfer coefficients in a perforated rotating disc contactor. Chin. J. Chem. Eng. 2017, 25, 53-61. [CrossRef]

16. Khovanskyi, S.; Pavlenko, I.; Pitel, J.; Mizakova, J.; Ochowiak, M.; Grechka, I. Solving the coupled aerodynamic and thermal problem for modeling the air distribution devices with perforated plates. Energies 2019, 12, 3488. [CrossRef]

17. Ostroha, R.; Yukhymenko, M.; Lytvynenko, A.; Bocko, J.; Pavlenko, I. Granulation process of the organic suspension: Fluidized bed temperature influence on the kinetics of the granule formation. In Advances in Design, Simulation and Manufacturing (DSMIE 2018). Lecture Notes in Mechanical Engineering; Ivanov, V., Rong, Y., Trojanowska, J., Venus, J., Liaposhchenko, O., Zajac, J., Pavlenko, I., Edl, M., Peraković, D., Eds.; Springer: Cham, Switzerland, 2019; pp. 463-471.

18. Merzliakov, I.; Pavlenko, I.; Chekh, O.; Sharapov, S.; Ivanov, V. Mathematical modeling of operating process and technological features for designing the vortex type liquid-vapor jet apparatus. In Advances in Design, Simulation and Manufacturing II. (DSMIE 2019). Lecture Notes in Mechanical Engineering; Ivanov, V., Trojanowska, J., Machado, J., Liaposhchenko, O., Zajac, J., Pavlenko, I., Edl, M., Perakovic, D., Eds.; Springer: Cham, Switzerland, 2020; pp. 613-622. 
19. Xiao, F.; Jing, J.; Kuang, S.; Yang, L.; Yu, A. Capillary forces on wet particles with a liquid bridge transition from convex to concave. Powder Technol. 2020, 363, 59-73. [CrossRef]

20. Murase, K.; Arai, K.; Ootsuka, T.; Sakamoto, D.; Egawa, F. Numerical and experimental estimation on the normal and tangential capillary bridge force adhered to two spheres. In Proceedings of the Handling and Processing of Granular Systems 2018-Topical at the 8th World Congress on Particle Technology, Orlando, FL, USA, 22-26 April 2018; AIChE: New York, NY, USA, 2018; pp. 46-53.

21. Wei, M.R.; Liu, F.; Wen, H.; Liu, Y.C.; Zhang, Y.S. Dispersion equation of three-dimensional unstable disturbing wave on surface of a viscous liquid jet with evaporating. Neiranji Xuebao Trans. CSICE (Chin. Soc. Intern. Combust. Engines) 2005, 23, 430-435.

22. Tammisola, O.; Lundell, F.; Daniel Söderberg, L. Surface tension-induced global instability of planar jets and wakes. J. Fluid Mech. 2012, 713, 632-658. [CrossRef]

23. Driessen, T.; Sleutel, P.; Dijksman, F.; Jeurissen, R.; Lohse, D. Control of jet breakup by a superposition of two Rayleigh-Plateau-unstable modes. J. Fluid Mech. 2014, 749, 275-296. [CrossRef]

24. Itoh, K.; Tsuji, Y.; Nakamura, H.; Kukita, Y. Free-Surface Shear Layer Instabilities on a High-Speed Liquid Jet. Fusion Sci. Technol. 2000, 37, 74-88. [CrossRef]

25. Jia, B.Q.; Xie, L.; Cui, X.; Yang, L.J.; Fu, Q.F. Linear stability of confined coaxial jets in the presence of gas velocity oscillations with heat and mass transfer. Phys. Fluids 2019, 31, 9145.

26. Jiang, X.S.; Qi, L.H.; Luo, J.; Zeng, X.H. Influences of disturbance frequency on the droplet generation for microdroplet deposition manufacture. Proc. Inst. Mech. Eng. Part B J. Eng. Manuf. 2009, 223, 1529-1539. [CrossRef]

27. Xie, R.; Chu, L.Y.; Chen, W.M.; Zhao, Y.; Xiao, X.C.; Wang, S. Preparation of monodispersed porous microcapsule membranes with SPG membrane emulsification and interfacial polymerization. Gao Xiao Hua Xue Gong Cheng Xue Bao J. Chem. Eng. Chin. Univ. 2003, 17, 400-405.

28. Mu, K.; Si, T.; Li, E.; Xu, R.X.; Ding, H. Numerical study on droplet generation in axisymmetric flow focusing upon actuation. Phys. Fluids 2018, 30, 9601. [CrossRef]

29. Chen, X.; Ren, C.L. Experimental study on droplet generation in flow focusing devices considering a stratified flow with viscosity contrast. Chem. Eng. Sci. 2017, 163, 1-10. [CrossRef]

30. Fesenko, A.; Basova, Y.; Ivanov, V.; Ivanova, M.; Yevsiukova, F.; Gasanov, M. Increasing of equipment efficiency by intensification of technological processes. Period. Polytech. Mech. Eng. 2019, 63, 67-73. [CrossRef]

31. Straka, L.; Panda, A. Optimal preventive maintenance schedule of slewing rings for demanding production machine. MM Sci. J. 2018, 12, 2696-2700. [CrossRef]

32. Lytvynenko, A.; Yukhymenko, M.; Pavlenko, I.; Pitel, J.; Mizakova, J.; Lytvynenko, O.; Ostroha, R.; Bocko, J. Ensuring the reliability of pneumatic classification process for granular material in a rhomb-shaped apparatus. Appl. Sci. 2019, 9, 1604. [CrossRef]

33. Chao, C.; Xu, G.; Fan, X. Effect of surface tension, viscosity, pore geometry and pore contact angle on effective pore throat. Chem. Eng. Sci. 2019, 197, 269-279. [CrossRef]

34. Bilonoga, Y.; Maksysko, O. The laws of distribution of the values of turbulent thermo-physical characteristics in the volume of the flows of heat carriers taking into account the surface forces. Int. J. Heat Technol. 2019, 37, 1-10. [CrossRef]

35. Jiang, H.; Tan, H. One-dimensional simulation of drop breakup in inkjet. In Advanced Materials-TechConnect Briefs 2017; TechConnect: San Juan Capistrano, CA, USA, 2017; Volume 4, pp. 128-132.

36. Nazari, A.; Nazari, A. Experimental investigation on Newtonian drop formation in different continuous phase fluids. In Proceedings of the ASME International Mechanical Engineering Congress and Exposition, Proceedings (IMECE), Pittsburgh, PA, USA, 9-15 November 2018; American Society of Mechanical Engineers (ASME): New York, NY, USA, 2018; Volume 7, p. 144113.

37. Rajendran, S.; Jog, M.A.; Manglik, R.M. Experimental investigation of jet breakup at low weber number. At. Sprays 2017, 27, 821-834. [CrossRef]

38. Tothova, M.; Pitel, J. Dynamic simulation of pneumatic muscle actuator in Matlab/Simulink environment. In Proceedings of the 2014 IEEE 12th International Symposium on Intelligent Systems and Informatics (SISY), Subotica, Serbia, 11-13 September 2014; pp. 209-213. 
39. Mižáková, J.; Pitel', J.; Hošovský, A.; Kolarčík, M.; Ratnayake, M. Using special filter with membership function in biomass combustion process control. Appl. Sci. 2018, 8, 1279. [CrossRef]

40. Zidek, K.; Maxim, V.; Pitel, J.; Hosovsky, A. Embedded vision equipment of industrial robot for inline detection of product errors by clustering-classification algorithms. Int. J. Adv. Robot. Syst. 2016, 13, 4901. [CrossRef] 